\title{
Analisis Postur Kerja Operator Pemanen Kelapa Sawit dengan Metode Quick Exposure Check (QEC)
}

\author{
Faradila Ananda Yul, Saputra \\ Program Studi Teknik Industri, Fakultas Teknik, Universitas Muhammadiyah Riau \\ Jalan Tuanku Tambusai Ujung, Kecamatan Tampan, Kelurahan Delima, Kota Pekanbaru, Riau 28291 \\ E-mail : faradila@umri.ac.id
}

\begin{abstract}
PT. Sandria Sukses Bersama is a company engaged in oil palm plantations. Oil palm harvesting activities are carried out using egrek tools. The activity is carried out on hilly land which is quite steep with the age of 16 years old oil palm trees with tree heights reaching 10-15 meters. This condition causes operators to tend to tilt their heads up when doing work so operators often complain of feeling pain in their necks and legs. This study was conducted with the aim of analyzing the work posture of oil palm harvesting operators in carrying out their work. The results of this study indicate that the operator's exposure score with an average of $88.97 \%$. This value is at exposure level 4 which is $71-100 \%$ which indicates that the working posture of oil palm harvesting at PT. Sandria Sukses Bersama needs to take action now because it is very risky for work-related injuries if it is carried out continuously.
\end{abstract}

Keywords : Work Posture, Exposure Score, Exposure Level

\begin{abstract}
Abstrak
PT. Sandria Sukses Bersama merupakan perusahaan yang bergerak dibidang perkebunan kelapa sawit. Aktivitas pemanenan kelapa sawit dilakukan dengan menggunakan alat egrek. Aktivitas tersebut dilakukan di lahan perbukitan yang cukup curam dengan usia pohon kelapa sawit yang sudah berusia 16 tahun dengan ketinggian pohon mencapai 1015 meter. Kondisi ini menyebabakan operator cenderung mengadahkan kepala keatas saat melakukan pekerjaan sehingga operator sering mengeluh merasakan sakit pada bagian leher dan kaki mereka. Penelitian ini dilakukan dengan tujuan menganalisis postur kerja operator panen kelapa sawit dalam melakukan pekerjaan. Hasil dari penelitian ini menunjukkan bahwa exposure score operator dengan rata-rata yaitu 88,97\%. Nilai tersebut berada pada exposure level 4 yaitu 71-100\% yang menunjukkan bahwa postur kerja panen kelapa sawit pada PT. Sandria Sukses Bersama perlu dilakukan tindakan sekarang juga karena sangat beresiko terjadi cedera akibat kerja apabila dilakukan secara terus menerus.
\end{abstract}

Kata Kunci : Postur Kerja, Exposure Score, Exposure Level

\section{Pendahuluan}

Perusahaan yang bergerak dibidang perkebunan memerlukan sumber daya alam dan sumber daya manusia yang bagus. Untuk mewujudkan hal tersebut perlu dilakukan perawatan dan pemanenan yang dilakukan oleh tenaga kerja yang berkompeten dibidangnya. Selain itu, kondisi kerja juga sangat berpengaruh pada produktifitas pekerja dalam suatu perusahaan. Kondisi kerja yang baik adalah kondisi kerja yang nyaman, aman, sehat, efektif dan efisien. Apabila kondisi kerja tidak nyaman maka akan menimbulkan suatu masalah diantaranya cedera pada pekerja. Pada saat ini masih banyak perusahaan yang belum memperhatikan Kesehatan pekerja ketika melaksanakan pekerjaannya.

PT. Sandria Sukses Bersama merupakan perusahaan yang bergerak dibidang perkebunan kelapa sawit. PT. Sandria Sukses Bersama melaksanakan panen kelapa sawit selama 6 hari dalam seminggu dan 6 sampai 10 jam dalam sehari. Dimana dalam melakukan pekerjaan, operator panen melakukannya dengan menggunakan alat yaitu egrek. Aktifitas tersebut dilakukan diatas 
lahan perbukitan yang tinggi dan dengan kondisi pohon kelapa sawit yang sudah tua yaitu 16 tahun dengan ketinggian pohon mencapai 10-15 meter. Kondisi ini menyebabkan operator cenderung mengadahkan kepala keatas pada saat melakukan pekerjaan sehingga operator sering mengeluh sakit pada bagian leher dan pada bagian kaki mereka.

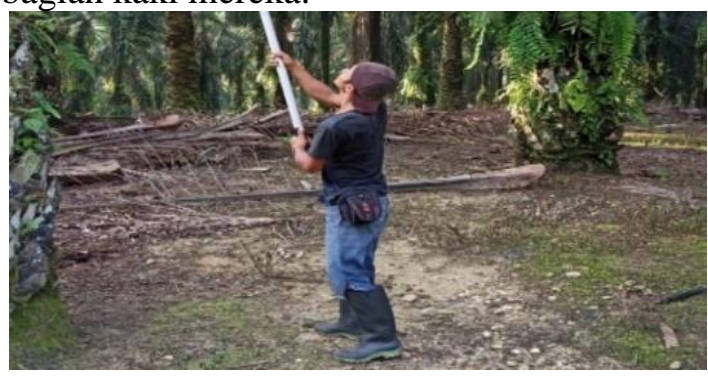

Gambar 1. Postur kerja operator panen kelapa sawit

Untuk itu perlu dilakukan penilaian postur kerja pada operator panen di PT. Sandria Sukses Bersama.

ergonomi adalah ilmu, teknologi dan seni untuk menserasikan peralatan, mesin, sistem, organisasi dan lingkungan pada kemampuan, kebolehan dan batasan manusia sehingga diperoleh kondisi kerja dan lingkungan yang sehat, aman, nyaman dan efisien sehingga tercapai produktivitas yang setinggi tingginya (Manuaba, 2000; Palilingan, 2013).

Quick Exposure Check (QEC) adalah salah satu metode pengukuran beban postur. Quick Exposure Check (QEC) mempunyai tingkat sensitivitas dan kegunaan yang tinggi serta dapat diterima secara luas realibilitasnya. Selain itu, Quick Exposure Check (QEC) digunakan untuk mengetahui risiko cedera pada otot rangka /sistem muskuloskeletal (muscoluskeletal disorder) yang menitik beratkan pada tubuh bagian atas yakni punggung, leher, bahu, dan pergelangan tangan. (Li dan Buckle, 1999).

Perhitungan nilai Exposure

dihitungan dengan rumus sebagai berikut:

Dimana :
$\mathrm{X}$

$=$ total Score yang diperoleh dari penilaian terhadap postur (punggung, bahu/lengan + pergelangan tangan + leher)

Xmaks $=$ total Score maksimum untuk postur kerja (punggung + bahu/lengan + pergelangan tangan + leher)

Nilai Exposure Level yang didapat digunakan sebagai acuan untuk menentukan tindakan yang harus dilakukan dari hasil perhitungan exposure score yang telah dilakukan. Tindakan yang diambil ditentukan berdasarkan tabel dibawah ini:

Tabel 1. Action Level QEC

\begin{tabular}{|c|c|l|c|}
\hline $\begin{array}{c}\text { Level } \\
\text { Tindakan }\end{array}$ & $\begin{array}{c}\text { Persentase } \\
\text { Skor }\end{array}$ & \multicolumn{1}{|c|}{ Tindakan } & $\begin{array}{c}\text { Total Skor } \\
\text { Exposure }\end{array}$ \\
\hline 1 & $0-40 \%$ & Aman & $32-70$ \\
\hline 2 & $41-50 \%$ & Diperlukan beberapa waktu kedepan & $71-88$ \\
\hline 3 & $51-70 \%$ & Tindakan dalam waktu dekat & $89-123$ \\
\hline 4 & $71-100 \%$ & Tindakan sekarang juga & $124-176$ \\
\hline
\end{tabular}

\section{Metodologi}

Analisis postur kerja yang dilakukan pada PT. Sandria Sukses Bersama dilakukan dengan menggunakan metode quick exposure check. Hal-hal yang perlu dilakukan dalam proses analisisnya adalah :

1. Penyebaran Standart Nordic Questioner kepada seluruh operator panen kelapa sawit.

2. Rekapitulasi hasil kuesioner SNQ dan menentukan tingkat kelelahan otot yang paling banyak terjadi.

3. Penyebaran kuesioner pengamat dan kuesioner operator.

4. Rekapitulasi hasil kuesioner pengamat dan kuesioner operator.

5. Perhitungan exposure score berdasarkan hasil rekapitulasi kuesioner pengamat dan kuesioner operator pada tabel score QEC.

6. Menentukan exposure level berdasarkan exposure score yang telah dilakukan.

7. Penentuan tindakan yang harus dilakukan berdasarkan exposure level. 


\section{Hasil dan Pembahasan}

Penentuan tingkat kelelahan otot yang terjadi pada operator panen kelapa sawit yang dilakukan berdasarkan Standart Nordic Questioner yang terlampir digunakan sebagai dasar pemilihan metode Quick Exposure Check. Adapun hasil rekapitulasi dari Standart Nordic Questioner adalah sebagai berikut:

Tabel 2. Rekapitulasi Standart Nordic Questioner

\begin{tabular}{|c|l|c|c|c|c|}
\hline \multirow{2}{*}{ No } & \multicolumn{1}{|c|}{ Jenis Keluhan } & \multicolumn{4}{|c|}{ Tingkat Keluhan } \\
\cline { 3 - 6 } & & $\begin{array}{c}\text { Tidak } \\
\text { Sakit }\end{array}$ & $\begin{array}{c}\text { Agak } \\
\text { Sakit }\end{array}$ & Sakit & $\begin{array}{c}\text { Sangat } \\
\text { Sakit }\end{array}$ \\
\hline 1 & sakit kaku di leher bagian atas & 3 & 7 & 9 & 0 \\
\hline 2 & sakit kaku di leher bagian bawah & 2 & 3 & 9 & 5 \\
\hline 3 & sakit di bahu kiri & 4 & 6 & 6 & 3 \\
\hline 4 & sakit di bahu kanan & 3 & 7 & 8 & 2 \\
\hline 5 & sakit lengan atas kiri & 3 & 4 & 6 & 5 \\
\hline 6 & sakit lengan atas kanan & 2 & 6 & 5 & 5 \\
\hline 7 & sakit di punggung & 2 & 6 & 10 & 1 \\
\hline 8 & sakit pada pinggang & 1 & 11 & 7 & 0 \\
\hline 9 & sakit pada bokong & 9 & 7 & 3 & 0 \\
\hline 10 & sakit pada pantat & 9 & 7 & 3 & 0 \\
\hline 11 & sakit pada siku kiri & 4 & 9 & 6 & 0 \\
\hline 12 & sakit pada siku kanan & 4 & 11 & 3 & 1 \\
\hline 13 & sakit pada lengan bawah kiri & 3 & 5 & 11 & 0 \\
\hline 14 & sakit pada lengan bawah kanan & 2 & 9 & 8 & 0 \\
\hline 15 & sakit pada pergelangan tangan kiri & 5 & 11 & 2 & 1 \\
\hline 16 & sakit pada pergelangan tangan kanan & 2 & 7 & 10 & 0 \\
\hline 17 & sakit pada tangan kiri & 6 & 8 & 5 & 0 \\
\hline 18 & sakit pada tangan kanan & 6 & 8 & 5 & 0 \\
\hline 19 & sakit pada paha kiri & 3 & 10 & 6 & 0 \\
\hline 20 & sakit pada paha kanan & 4 & 11 & 4 & 0 \\
\hline 21 & sakit pada lutut kiri & 5 & 7 & 6 & 1 \\
\hline 22 & sakit pada lutut kanan & 4 & 12 & 2 & 1 \\
\hline 23 & sakit pada betis kiri & 6 & 4 & 9 & 0 \\
\hline 24 & sakit pada betis kanan & 3 & 8 & 8 & 0 \\
\hline 25 & sakit pada pergelangan kaki kiri & 7 & 10 & 2 & 0 \\
\hline 26 & sakit pada pergelangan kaki kanan & 5 & 11 & 3 & 0 \\
\hline 27 & sakit pada kaki kiri & 6 & 7 & 6 & 0 \\
\hline 28 & sakit pada kaki kanan & 3 & 9 & 6 & 0 \\
\hline
\end{tabular}

Setelah dilakukan penyebaran Standart Nordic Questioner dan telah didapatkan metode yang sesuai dengan tingkat kelelahan yang terjadi maka selanjutnya buat tabel penilaian pengamat dan peneliti. Berikut ini merupakan tabel penilaian pengamat dan peneliti adalah:
Tabel 3. Penilaian Pengamat dan Operator

\begin{tabular}{|c|c|c|c|c|c|c|}
\hline FAKTOR & KODE & 1 & 2 & 3 & 4 & 5 \\
\hline PUNGGUNG & A & $\begin{array}{c}\text { Hampir } \\
\text { lurus }\end{array}$ & Agak & Terlalu & & \\
\hline FREKUENSI & B & Tidak & Iya & 3 kali & 8 Kali & $\begin{array}{c}\text { Lebih } 12 \\
\text { Kali }\end{array}$ \\
\hline BAHU & C & \begin{tabular}{|c|} 
Sekitar \\
punggung
\end{tabular} & $\begin{array}{c}\text { Sekitar } \\
\text { dada }\end{array}$ & $\begin{array}{c}\text { Sekitar } \\
\text { Bahu }\end{array}$ & & \\
\hline LENGAN & D & Jarang & Sering & $\begin{array}{c}\text { Sangat } \\
\text { Sering }\end{array}$ & & \\
\hline $\begin{array}{l}\text { PERGELANGAN } \\
\text { TANGAN }\end{array}$ & E & $\begin{array}{c}\text { Hampir } \\
\text { lurus }\end{array}$ & Tertekuk & & & \\
\hline TANGAN & F & 10 kali & $11-20$ kali & $\begin{array}{c}\text { Lebih } 20 \\
\text { kali }\end{array}$ & & \\
\hline LEHER & G & Tidak & \begin{tabular}{|c|}
$\begin{array}{c}\text { Terkadan } \\
\mathrm{g}\end{array}$ \\
\end{tabular} & $\begin{array}{c}\text { Terus } \\
\text { menerus }\end{array}$ & & \\
\hline BEBAN & $\mathrm{H}$ & Ringan & Cukup & Berat & $\begin{array}{r}\text { Sangat } \\
\text { Berat }\end{array}$ & \\
\hline DURASI & I & $\begin{array}{c}\text { Kurang 2 } \\
\text { jam }\end{array}$ & $2-4$ jam & $\begin{array}{c}\text { Lebih } 4 \\
\text { jam }\end{array}$ & & \\
\hline $\begin{array}{l}\text { KEKUATAN } \\
\text { TANGAN }\end{array}$ & $\mathrm{J}$ & Rendah & Sedang & Tinggi & & \\
\hline VISUAL & K & Rendah & Tinggi & & & \\
\hline $\begin{array}{l}\text { PENGGUNAAN } \\
\text { KENDARAAN }\end{array}$ & $\mathrm{L}$ & $\begin{array}{r}\text { Tidak } \\
\text { pernah }\end{array}$ & $1-4$ jam & $\begin{array}{c}\text { Lebih } 4 \\
\text { jam }\end{array}$ & & \\
\hline GETARAN & M & $\begin{array}{l}\text { Tidak } \\
\text { pernah }\end{array}$ & $1-4 \mathrm{jam}$ & $\begin{array}{c}\text { Lebih } 4 \\
\text { jam }\end{array}$ & & \\
\hline $\begin{array}{l}\text { TINGKAT } \\
\text { KESULITAN }\end{array}$ & $\mathrm{N}$ & $\begin{array}{c}\text { Tidak } \\
\text { pernah }\end{array}$ & \begin{tabular}{|c|} 
Terkadan \\
$\mathrm{g}$ \\
\end{tabular} & Sering & & \\
\hline TINGKAT STRES & $\mathrm{O}$ & $\begin{array}{l}\text { Tidak } \\
\text { Setres }\end{array}$ & $\begin{array}{l}\text { Cukup } \\
\text { Setres }\end{array}$ & Setres & $\begin{array}{l}\text { Sangat } \\
\text { Setres }\end{array}$ & \\
\hline
\end{tabular}

\subsection{Perhitungan Exposure Score}

Pada perhitungan Exposure Score diawali dengan rekapitulasi hasil kuesioner pengamat dan kuesioner operator. Adapun hasil pada kuesioner pengamat di kelompokkan yakni A, B, C, D, E, F, dan G. sedangkan hasil pada kuesioner operator di kelompokkan yakni $\mathrm{H}$, I, J, K, L, M, N, dan O. berikut ini merupakan rekapitulasi kuesioner pengamat yang telah dilakukan adalah: 
Tabel 4. Rekapitulasi Kuesioner Pengamat

\begin{tabular}{|c|l|c|c|c|c|c|c|c|}
\hline Ope rator & Nama Ope rator & A & B & C & D & E & F & G \\
\hline 1 & Mardius & A2 & B5 & C3 & D3 & E1 & F3 & G3 \\
\hline 2 & Sudarsono & A2 & B5 & C3 & D3 & E1 & F3 & G3 \\
\hline 3 & Wangsa & A2 & B5 & C3 & D3 & E1 & F3 & G3 \\
\hline 4 & Dory & A2 & B5 & C3 & D3 & E1 & F3 & G3 \\
\hline 5 & Yustinus & A2 & B5 & C3 & D3 & E1 & F3 & G3 \\
\hline 6 & Juanda & A2 & B5 & C3 & D3 & E1 & F3 & G3 \\
\hline 7 & Sepianuh & A2 & B5 & C3 & D3 & E1 & F3 & G3 \\
\hline 8 & Delizato & A2 & B5 & C3 & D3 & E1 & F3 & G3 \\
\hline 9 & Elvinus & A2 & B5 & C3 & D3 & E1 & F3 & G3 \\
\hline 10 & Didik P. & A2 & B5 & C3 & D3 & E1 & F3 & G3 \\
\hline 11 & Rinto & A2 & B5 & C3 & D3 & E1 & F3 & G3 \\
\hline 12 & Anwar & A2 & B5 & C3 & D3 & E1 & F3 & G3 \\
\hline 13 & April & A2 & B5 & C3 & D3 & E1 & F3 & G3 \\
\hline 14 & Edy P. & A2 & B5 & C3 & D3 & E1 & F3 & G3 \\
\hline 15 & Jaka S. & A2 & B5 & C3 & D3 & E1 & F3 & G3 \\
\hline 16 & Irwan & A2 & B5 & C3 & D3 & E1 & F3 & G3 \\
\hline 17 & Legino & A2 & B5 & C3 & D3 & E1 & F3 & G3 \\
\hline 18 & Novelius & A2 & B5 & C3 & D3 & E1 & F3 & G3 \\
\hline 19 & Anggiat & A2 & B5 & C3 & D3 & E1 & F3 & G3 \\
\hline
\end{tabular}

Berikut ini merupakan hasil rekapitulasi kuesioner operator yang dilakukan pada operator panen kelapa sawit adalah :

Tabel 5. Rekapitulasi Kuesioner Operator

\begin{tabular}{|c|l|c|c|c|c|c|c|c|c|}
\hline Operator & Nama Operator & H & I & J & K & L & M & N & O \\
\hline 1 & Mardius & H2 & I3 & J2 & K2 & L1 & M1 & N2 & O1 \\
\hline 2 & Sudarsono & H3 & I3 & J3 & K2 & L1 & M1 & N2 & O1 \\
\hline 3 & Wangsa & H2 & I3 & J3 & K2 & L1 & M1 & N2 & O2 \\
\hline 4 & Dory & H3 & I3 & J3 & K2 & L1 & M1 & N2 & O2 \\
\hline 5 & Yustinus & H2 & I3 & J3 & K2 & L1 & M1 & N2 & O2 \\
\hline 6 & Juanda & H2 & I3 & J3 & K1 & L1 & M1 & N2 & O2 \\
\hline 7 & Sepianuh & H3 & I3 & J2 & K2 & L1 & M1 & N2 & O1 \\
\hline 8 & Delizato & H3 & I3 & J3 & K2 & L1 & M1 & N2 & O1 \\
\hline 9 & Elvinus & H2 & I3 & J3 & K2 & L1 & M1 & N2 & O1 \\
\hline 10 & Didik P. & H2 & I3 & J2 & K2 & L1 & M1 & N2 & O2 \\
\hline 11 & Rinto & H2 & I3 & J3 & K2 & L1 & M1 & N2 & O1 \\
\hline 12 & Anwar & H3 & I3 & J3 & K2 & L1 & M1 & N2 & O1 \\
\hline 13 & April & H3 & I3 & J2 & K2 & L1 & M1 & N2 & O1 \\
\hline 14 & Edy P. & H3 & I3 & J3 & K2 & L1 & M1 & N2 & O1 \\
\hline 15 & Jaka S. & H3 & I3 & J2 & K2 & L1 & M1 & N2 & O1 \\
\hline 16 & Irwan & H3 & I3 & J3 & K2 & L1 & M1 & N2 & O1 \\
\hline 17 & Legino & H2 & I3 & J3 & K2 & L1 & M1 & N2 & O2 \\
\hline 18 & Novelius & H2 & I3 & J3 & K2 & L1 & M1 & N2 & O2 \\
\hline 19 & Anggiat & H3 & I3 & J2 & K2 & L1 & M1 & N2 & O2 \\
\hline
\end{tabular}

Setelah didapatkan hasil rekapitulasi dari kuesioner pengamat dan kuesioner operator. Kemudian dilakukan perhitungan menggunakan tabel score Quick Exposure Check pada jenis pekerjaan Manual Handling. Dibawah ini merupakan contoh perhitungan Exposure Score pada operator 1 di PT. Sandria Sukses Bersama adalah sebagai berikut :
Tabel 6. Perhitungan Exposure Level Operator 1

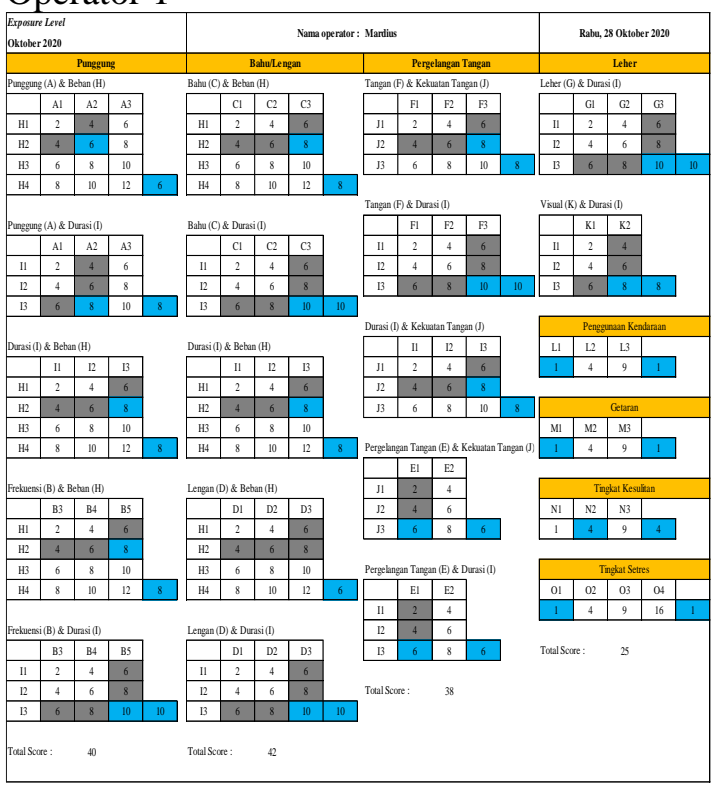

\subsection{Hasil Exposure Score}

Berikut ini merupakan rekapitulasi hasil Exposure Score untuk 19 operator pada PT. Sandria Sukses Bersama adalah sebagai berikut :

Tabel 7. Hasil Rekapitulasi nilai Exposure Score

\begin{tabular}{|c|c|c|c|c|c|c|c|c|c|c|}
\hline $\begin{array}{c}\text { Anggota Tubuh Yang } \\
\text { Diamati }\end{array}$ & $\begin{array}{c}\mathrm{OP} \\
1\end{array}$ & $\begin{array}{c}\text { OP } \\
2\end{array}$ & $\begin{array}{c}\text { OP } \\
3\end{array}$ & $\begin{array}{c}\text { OP } \\
4\end{array}$ & $\begin{array}{c}\mathrm{OP} \\
5\end{array}$ & $\begin{array}{c}\text { OP } \\
6\end{array}$ & $\begin{array}{c}\text { OP } \\
7\end{array}$ & $\begin{array}{c}\text { OP } \\
8\end{array}$ & $\begin{array}{c}\text { OP } \\
9\end{array}$ & $\begin{array}{l}\text { OP } \\
10\end{array}$ \\
\hline Punggung & 40 & 46 & 40 & 46 & 40 & 40 & 46 & 46 & 40 & 40 \\
\hline Bahu/Lengan & 42 & 50 & 44 & 50 & 44 & 44 & 50 & 50 & 44 & 44 \\
\hline Pergelangan Tangan & 38 & 42 & 42 & 42 & 42 & 42 & 36 & 42 & 42 & 36 \\
\hline $\begin{array}{l}\text { Leher, kendaraan, } \\
\text { getaran, kesulitan, stress }\end{array}$ & 25 & 25 & 28 & 28 & 28 & 26 & 25 & 25 & 25 & 28 \\
\hline Total & 145 & 163 & 154 & 166 & 154 & 152 & 157 & 163 & 151 & 148 \\
\hline \multicolumn{11}{|c|}{ Total Rata-rata Exposure } \\
\hline
\end{tabular}

Tabel 8. Hasil Rekapitulasi nilai Exposure Score (Lanjutan)

\begin{tabular}{|c|c|c|c|c|c|c|c|c|c|c|}
\hline $\begin{array}{c}\text { Anggota Tubuh Yang } \\
\text { Diamati }\end{array}$ & $\begin{array}{c}\text { OP } \\
11 \\
\end{array}$ & $\begin{array}{l}\mathrm{OP} \\
12\end{array}$ & $\begin{array}{l}\text { OP } \\
13\end{array}$ & \begin{tabular}{|l|} 
OP \\
14 \\
\end{tabular} & $\begin{array}{l}\text { OP } \\
15\end{array}$ & $\begin{array}{l}\text { OP } \\
16\end{array}$ & $\begin{array}{l}\text { OP } \\
17\end{array}$ & \begin{tabular}{l|} 
OP \\
18 \\
\end{tabular} & \begin{tabular}{|c|} 
OP \\
19 \\
\end{tabular} & Rata-rata \\
\hline Punggung & 40 & 46 & 46 & 46 & 46 & 46 & 40 & 40 & 46 & 43,33 \\
\hline Bahu/Lengan & 44 & 50 & 50 & 50 & 50 & 50 & 44 & 44 & 50 & 47,33 \\
\hline Pergelangan Tar & 42 & 42 & 36 & 42 & 36 & 42 & 42 & 42 & 36 & 40,33 \\
\hline $\begin{array}{l}\text { Leher, kendar } \\
\text { getaran, kesul }\end{array}$ & 25 & 25 & 25 & 25 & 25 & 25 & 28 & 28 & 28 & 26,22 \\
\hline Total & 151 & 163 & 157 & 163 & 157 & 163 & 154 & 154 & 160 & 156,58 \\
\hline \multicolumn{10}{|c|}{ Total Rata-rata Exposure } & 156,58 \\
\hline
\end{tabular}

\subsection{Perhitungan Nilai Action Level QEC}

Nilai Action Level QEC digunakan untuk mengetahui tindakan yang harus diambil akibat adanya posturkerja dari operator setelah 
dilakukan perhitungan. Perhitungan Action Level dibuat berdasarkan hasil dari Exposure Score QEC pada tabel 7 dan tabel 8. Nilai Action Level QEC dapat dihitung sebagai berikut :

$$
\begin{aligned}
& E(\%)=\frac{X}{X_{\text {maks }}} x 100 \% \\
& E(\%)=\frac{145}{176} x 100 \% \\
& E(\%)=82,39 \%
\end{aligned}
$$

Nilai Action Level QEC pada operator 1 diperoleh $82,39 \%$, jika dilihat pada tabel Exposure Level pada tabel 1, maka postur kerja tersebut dikatakan beresiko tinggi akan terjadi sakit pada bagian leher, tangan, kaki, dan tulang belakang sehingga perlu dilakukan tindakan sekarang juga.

Berikut ini merupakan rekapitulasi nilai Action Level untuk semua operator panen kelapa sawit adalah:

\section{Tabel 9.}

Rekapitulasi Nilai Action Level

\begin{tabular}{|c|c|c|c|c|}
\hline Nama Operator & $\begin{array}{c}\text { Jumlah } \\
\text { Score }\end{array}$ & $\begin{array}{c}\text { Nilai Action Level } \\
\text { QEC }\end{array}$ & $\begin{array}{c}\text { Level } \\
\text { Tindakan }\end{array}$ & Tindakan \\
\hline Mardius & 145 & $82,39 \%$ & 4 & Tindakan sekarang juga \\
\hline Sudarsono & 163 & $92,61 \%$ & 4 & Tindakan sekarang juga \\
\hline Wangsa & 154 & $87,50 \%$ & 4 & Tindakan sekarang juga \\
\hline Dory & 166 & $94,32 \%$ & 4 & Tindakan sekarang juga \\
\hline Yustinus & 154 & $87,50 \%$ & 4 & Tindakan sekarang juga \\
\hline Juanda & 152 & $86,36 \%$ & 4 & Tindakan sekarang juga \\
\hline Sepianuh & 157 & $89,20 \%$ & 4 & Tindakan sekarang juga \\
\hline Delizato & 163 & $92,61 \%$ & 4 & Tindakan sekarang juga \\
\hline Elvinus & 151 & $85,80 \%$ & 4 & Tindakan sekarang juga \\
\hline Didik P. & 148 & $84,09 \%$ & 4 & Tindakan sekarang juga \\
\hline Rinto & 151 & $85,80 \%$ & 4 & Tindakan sekarang juga \\
\hline Anwar & 163 & $92,61 \%$ & 4 & Tindakan sekarang juga \\
\hline April & 157 & $89,20 \%$ & 4 & Tindakan sekarang juga \\
\hline Edy P. & 163 & $92,61 \%$ & 4 & Tindakan sekarang juga \\
\hline Jaka S. & 157 & $89,20 \%$ & 4 & Tindakan sekarang juga \\
\hline Irwan & 163 & $92,61 \%$ & 4 & Tindakan sekarang juga \\
\hline Legino & 154 & $87,50 \%$ & 4 & Tindakan sekarang juga \\
\hline Novelius & 154 & $87,50 \%$ & 4 & Tindakan sekarang juga \\
\hline Anggiat & 160 & $90,91 \%$ & 4 & Tindakan sekarang juga \\
\hline
\end{tabular}

Seperti pada tabel diatas, untuk semua operator nilai Action Level berada pada level 4 yang berarti perlu dilakukan tindakan sekarang juga.

\section{Kesimpulan}

Berdasarkan pengolahan data dan pembahasan Analisa pada penelitian ini maka disimpulkan bahwa hasil perhitungan postur tubuh pada operator panen kelapa sawit dengan menggunakan metode Quick Exposure Check, yaitu didapatkan semua operator berada di posisi action level 4 dengan rata-rata nilai Action Level adalah 88,97 \% yang berarti perlu dilakukan Tindakan sekarang juga.

\section{Daftar Pustaka}

[1] Ezi, Dkk. 2014. Usulan Perbaikan Stasiun Kerja pada PT. Sinar Advertama Servicindo (SAS) Berdasarkan Hasil Evaluasi Menggunakan Metode Quick Exposure Check (QEC), Institut Teknologi Bandung. Bandung.

[2] Grandjean, E. 1993. Fitting the Task to the Man. $4^{\text {th }}$ edition. London.

[3] Joko Priyono. 2014. Analisis Postur Kerja Dan Redesign Peralatan Kerja Menggunakan Metode Quick Exposure Check (QEC) Pada Operator Kerajinan Pencetakan Gerabah. Universitas Muhammadiyah Surakarta.

[4] Manuaba, A. 1999. Ergonomi, Kesehatan dan Keselamatan Kerja. Editor: Sritomo $W$ dan Stefanus E.W. Proceeding Seminar Nasional Ergonomi. Penerbit Guna Wijaya. Surabaya.

[5] Nurmianto, E. 2004. Ergonomi Konsep Dasar dan Aplikasinya. Penerbit Guna Widya. Edisi Kedua. Surabaya.

[6] Suma'mur, P.K. 1993. Ergonomi untuk Produktivitas Kerja. Yayasan Swabhawa Karya. Jakarta. 